\title{
THE EFFECT OF TOOTH PREPARATION TAPER ON THE MARGINAL FIT AND FRACTURE RESISTANCE OF CAD/CAM ZIRCONIA COPINGS
}

\author{
Emtair E $\mathrm{M}^{1} B D S$, Bakry $\mathrm{S}^{2} P h D$, Azer A $\mathrm{S}^{3} P h D$.
}

\begin{abstract}
: crown. Modifying axial wall tapering may influence on marginal fit and fracture resistance. copings. marginal fit and increased their fracture strength.

Key Words: CAD/CAM, all ceramic core, fit, resistance.

1. B.D.S. Faculty of Dentistry Sirte University of science and technology

2. Professor of Fixed Prosthodontics, Conservative Dentistry Department, Alexandria University.

3. Lecturer of Fixed Prosthodontics, Conservative Dentistry Department, Alexandria University.
\end{abstract}

Introduction: Clinical fracture resistance and marginal fit are regarded as major outcomes when considering the performance of all -ceramic

Objectives: To investigate the effect of tooth preparation taper on marginal adaption and fracture resistance of CAD/CAM zirconia ceramic

Materials and methods: A machined standard stainless steel dies representing lower first molar were made and fixed to a metal base to stimulate single prepared crowns with three different axial wall convergence angles $\left(6^{\circ}, 12^{\circ}, 22^{\circ}\right)$. Master dies were duplicated using silicon mold after which fifteen crowns were reproduced for each group using epoxy resin material. All cores were fabricated using cercon zirconia and adhesively luted on epoxy resin dies. Measurement of marginal fit was performed with cone beam computed tomography. Specimens were subjected to fracture resistance test. The failure modes and points of fracture will be recorded. Data were statistically analysed using ANOVA test.

Results: The results showed significant difference between three tested groups in marginal adaption, where 22 degree had significantly the best fit also there was significant difference between three tested groups in fracture resistance, where 22 degree have showed highest fracture load.

Conclusion: Within the limitations of this in vitro study, increasing the axial convergence angle of CAD/CAM zirconia core improved their

\section{INTRODUCTION}

Metal-free, all-ceramic restorations have become more widely distributed because of their high aesthetic potential and their excellent biocompatible properties.

Optimal esthetics and characteristics such as color stability, high wear resistance, and low thermal conductivity make all-ceramic materials ideal for the fabrication of fixed dental prostheses. However, their high fracture rates have limited the use of all-ceramic.

Several factors are associated with crack initiation and propagation in the restoration. These factors include; design of the restoration, micro- structure, size and distribution of surface flaws and residual stresses. In addition, the variation in the thickness of the restoration with different elastic modules and the magnitude of the applied load also play a significant role (1).

Resistance and retention forms of crown restoration are affected by the convergence angle of prepared teeth with all- ceramic crowns, a $10^{\circ}$ convergence angle has been recommended to obtain retention and retain strength with minimum tooth reduction, but convergence angles of up to $20^{\circ}$ have been considered acceptable.

It has been proposed that greater tooth preparation allowing increased thickness of all-ceramic crowns will increase their resistance to fracture (2). Similarly, a larger axial convergence angle of the preparation should increase the fracture strength of all-ceramic crowns.
The recent incorporation of Yttrium-partially stabilized Tetragonal Zirconia Polycrystals (Y-TZP) into dentistry along with the development of the Computer-Aided Design/Computer-Aided Manufacturing (CAD/CAM) technology has lead to a advance allowing the fabrication of all ceramic crowns and fixed partial dentures for the highly loaded molar area of the mouth (3).

Lack of adequate marginal fit is potentially detrimental to the supporting periodontal tissues. Imperfect restoration margins offer recesses for adherence of oral bacteria, which may cause secondary caries and/or gingival irritation $(4,5)$. Some in vitro studies on the internal or marginal adaptation of all-ceramic restoration have evaluated the influence of convergence angles, which affects adaptation of the fixed restoration.

The purpose of the present study was to evaluate the influence of different convergence angles on the marginal fit and fracture resistance of posterior zirconia ceramic copings fabricated with $\mathrm{CAD} / \mathrm{CAM}$ technology.

\section{MATERIALS AND METHODS}

Three machined milled standard stainless steel dies were prepared to stimulate lower first molar preparation to receive all ceramic crown with three different degrees of taper (Fig. 1).

The master stainless steel dies $\left(6^{\circ}, 12^{\circ}, 22^{\circ}\right.$ taper $)$ were duplicated using silicon mold after which fifteen crowns 
were produced using epoxy resin material having the same modulus of elasticity of dentin (RenCast ${ }^{\circledR}$ Epoxy Casting Resin, klybeckstrasse200, CH-4057 BASEL, Switzerland) (6).

Epoxy resin dies were divided into three groups, five specimens each according to the degree of taper (Fig. 2);

Group A: Axial wall tapering $22^{\circ}$ occlusally.

Group B: Axial wall tapering $12^{\circ}$ occlusally.

Group $C$ : Axial wall tapering $6^{\circ}$ occlusally.

The copings were manufactured by a CAD/CAM system and milled from semi-sintered zirconia blanks (Cercon Zirconia) (Dentsply DeguDent, GmbH Rodenbacher Chaussee 4 D-63457 Hanau-Wolfgang) (Fig. 3).

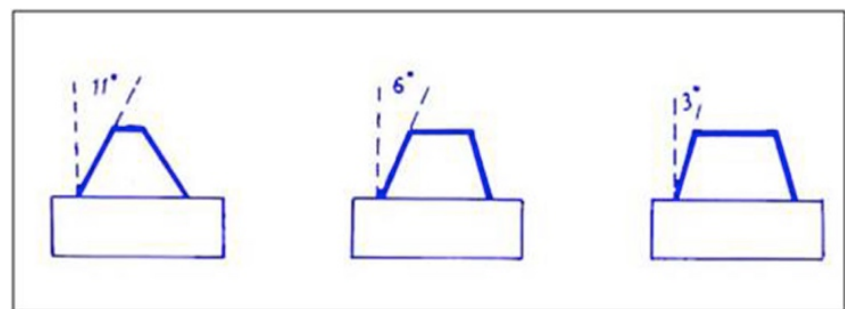

Fig. 1: Diagram showing three dies with different degree of taper.

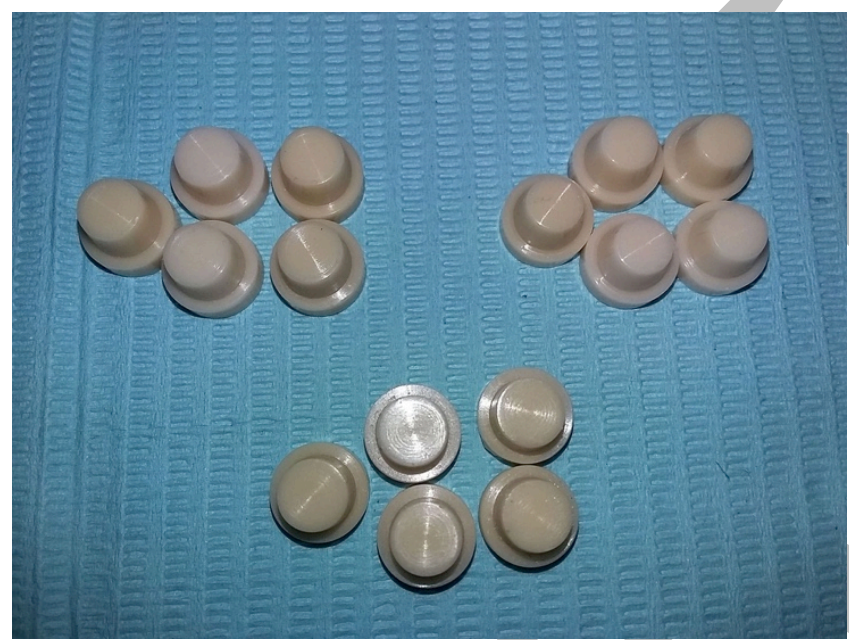

Fig. 2: Epoxy resin die.

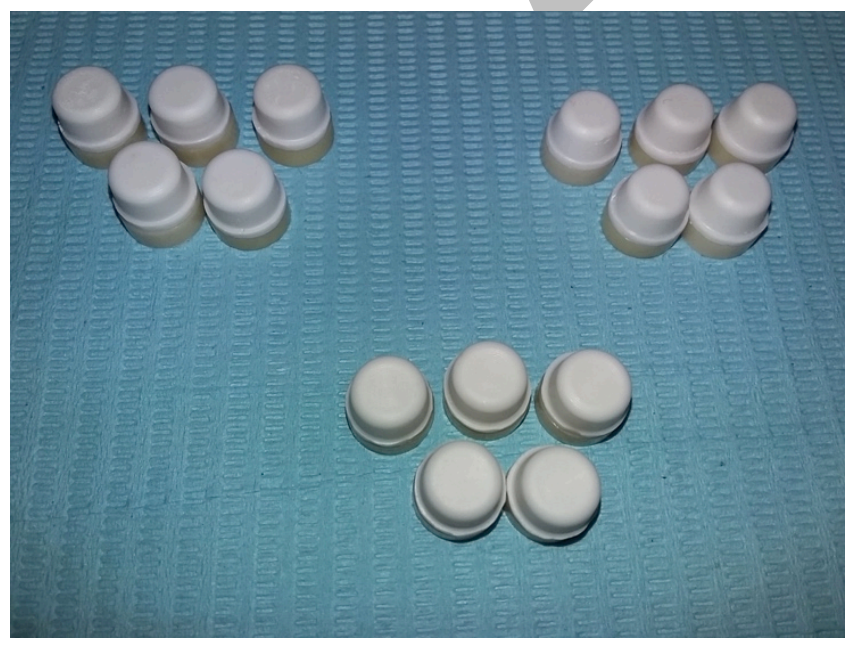

Fig. 3: Coping was seated onto its corresponding die.

\section{Fabrication of zirconia all-ceramic crowns}

\section{Optical impression of the specimens:}

In Cercon Smart Ceramic system, optical impressions were performed directly from epoxy resin dies instead of regular final impression; thus eliminating the need for stone dies fabrication.

First, cercon liquid was applied onto the prepared surface of the epoxy resin die using a brush, and was left for 1 minute to dry. It acts as an adhesive for the later used cercon powder. Next the powder sprayer was held 1-2 cm far from the epoxy die and the cercon powder was sprayed in a uniform layer on the surfaces of the specimen until a white powder layer covered the whole area. This cercon powder forms a reflection medium that is necessary for optical impression.

The digitalization of the dies was performed by a laser scanner (Cercon Eye). A proprietary three-camera system tracked a laser line reflection across the surface of the powdered die to obtain precision scans of all dies in 20 seconds each. The scanned data were then transmitted to the Cercon Art CAD software where images were displayed successively on the monitor in an enhanced threedimensional (3D) preview window for coping design.

\section{Designing of the copings using cercon software:}

The acquired optical data for each die was transferred into the Cercon Art CAD software on a computer which transformed it into an accurate three-dimensional digital dies, resembling original preparation with fine details of all surfaces and margins.

The desired design of crown coping was achieved through the software in sequenced steps using Cercon move navigation module, a 3-D navigation system for viewing objects on the screen from all angles - as if the framework was actually being held in the hand. The finish line was marked on the digital die of the prepared surface, anatomy of crown indicated by using a shape proposal for crown from data base and crown contours were adjusted by labeling the curvature lines of the crown.

During designing of proposed copings, standardization of size and morphology was taken into consideration. A uniform $0.5 \mathrm{~mm}$ thickness of occlusal and axial walls with a circumferential $1 \mathrm{~mm}$ marginal collar was indicated for all crowns.

\section{Milling of the zirconia copings}

Cercon base zirconia blanks were clamped in the Cercon Brain unit (milling chamber) and milled successively with a cylinder pointed bur. The milling process of each crown lasted for 10 minutes.

The zirconia blanks were then removed from the machine and milled zirconia copings were carefully separated from the blank using a diamond cutting bur. The sites of sprue-attachment of each milled coping were smoothed by a silicon carbide bur.

Because the sintering process is usually associated with volumetric shrinkage of the milled object, the cut from the blank showed expansion about 30\%. This expansion was 
also duplicated in the Cercon Brain unit component using a computer calculation after the scanning process.

\section{Firing of the milled zirconia copings}

The semi-sintered copings milled from Cercon base zirconia blanks were then placed in the Cercon Heat unit for sintering. The temperature cycle of Cercon Heat was precisely tailored to Cercon base. Because the cercon zirconia was particularly fine-grained, a "low" sinter temperature of $1350{ }^{\circ} \mathrm{C}$ was used.

The thickness of the fully sintered crown copings was checked using a digital caliper for a uniform $0.5 \mathrm{~mm}$ occlusal thickness, then the copings were seated onto their corresponding epoxy resin dies to check the fitting of the crown margins.

Composite resin cement (multilink cement system) (Ivoclar Vivadent AG, Bendererstr, Liechtenstein) was used for luting the coppings according to manufacturer's instructions.

The zirconia cores of the three groups were pretreated according to manufacturer's instructions for ceramic materials. The fitting surfaces were sandblasted with $50 \mu \mathrm{m}$ $\mathrm{A} 12 \mathrm{O} 3$ at pressure of 2.5 bars, rinsed with water spray for 60 seconds, and then dried with oil-free air. The Metal /Zirconia Primer was then applied in a thin layer using a micro-brush and left to react for 180 seconds and subsequently dried with oil-free air.

The resin dies were clean thoroughly with water and dried, Multilink Primer liquids A and B were mixed in a $1: 1$ mixing ratio and applied directly on the entire prepared surfaces of the epoxy die then scrubbed using a microbrush, and with a slight pressure for 15 seconds.

Multilink was applied soon after mixing to the internal surfaces of each crown, which was immediately seated on its respective prepared die with finger pressure then sustained under a static load of $5 \mathrm{~kg}$ using custom-made static device for 10 minutes. Excess cement at margins was removed immediately with a scaler (Fig. 4).

The marginal adaptation of cercon zirconia CAD/CAM cores of different degrees of taper were examined using cone beam computed tomography (Cone beam computed tomography (Galileos Sirona, IL 60172 Tel. 6305292300 6305292300 Fax 630529 1929).

Cone beam computed tomography provided four sagital cuts and four coronal cuts for each core, one measurement was recorded for each cut in order to standardize the measurement taken of each core with total of 8 measurements (Fig. 5).

To determine the fracture resistance of all groups (A, B and $\mathrm{C}$ ), a universal testing machine was used to record load in kilograms at which each crown would fracture; indicating the fracture resistance of the tested core.

Cores were fixed in a specially-designed metal ring that was fabricated to hold the sample in place during fracture test. The ring itself was fixed above a metal plate; which was fixed on the lower jaw of the universal testing machine.

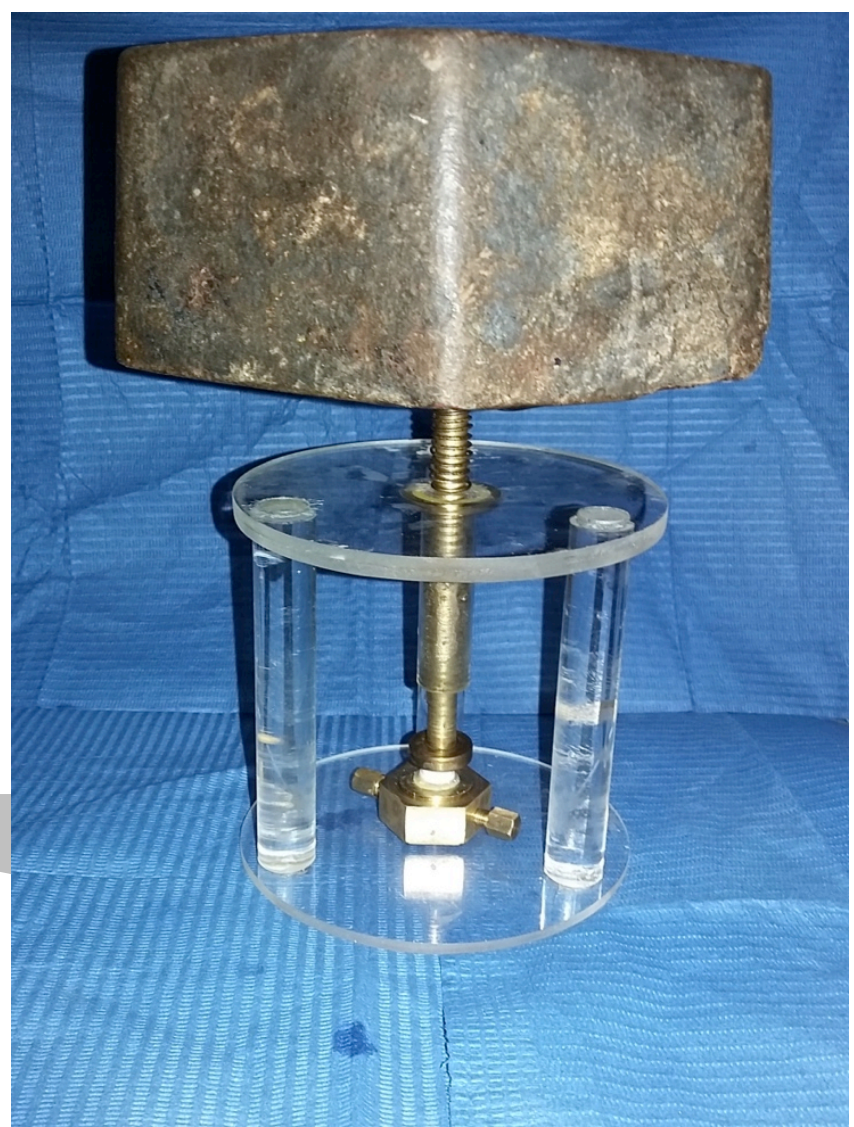

Fig. 4: Custom-made load device.

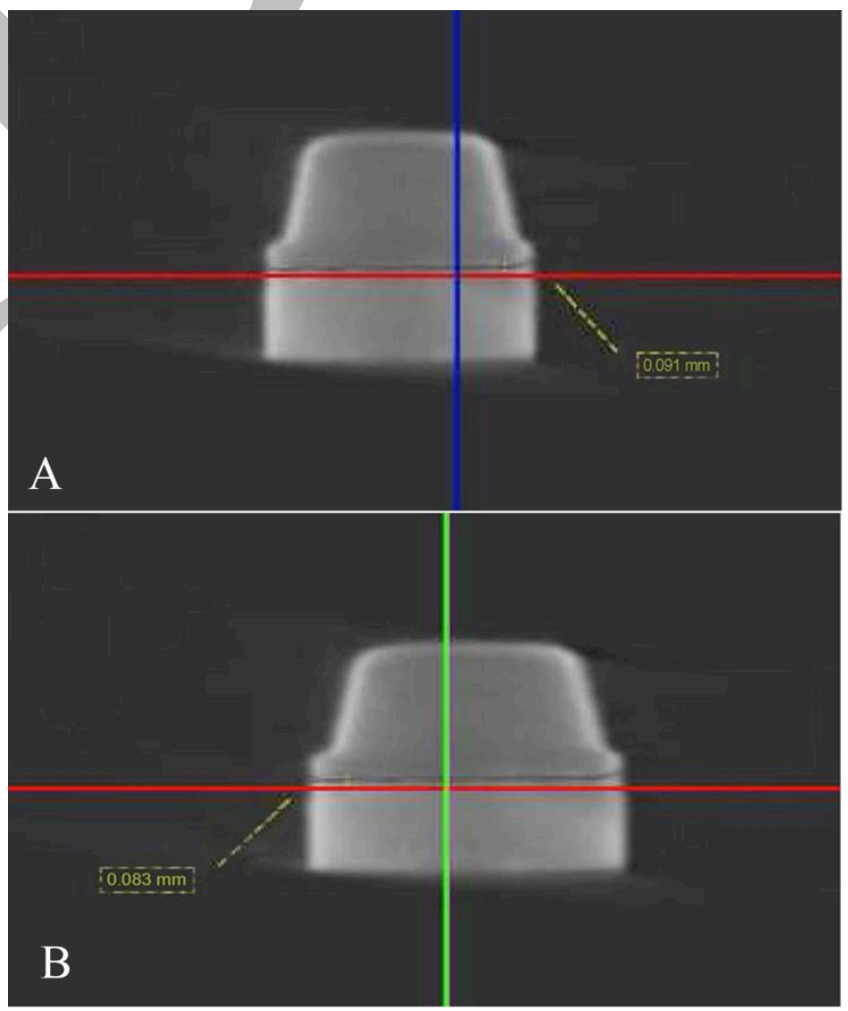

Fig. 5: Cone beam computed tomography measuring the marginal gap. (sagital (A) and coronal cut (B)). 
A $6 \mathrm{~mm}$ diameter stainless-steel ball stylus was installed in the upper jaw of the testing machine. A vertical compressive load was applied by means of the stylus and testing load was directed downwards on the long axis of each molar crown in the middle occlusal surface. A rubber sheet was used to distribute the applied force equally and avoid un-even contact (Fig. 6).

The load was applied with a cross-head speed of 0.5 $\mathrm{mm} / \mathrm{min}$ until fracture of zirconia core specimens had occurred. The failure load was viewed in kilograms on a reading monitor for each sample.

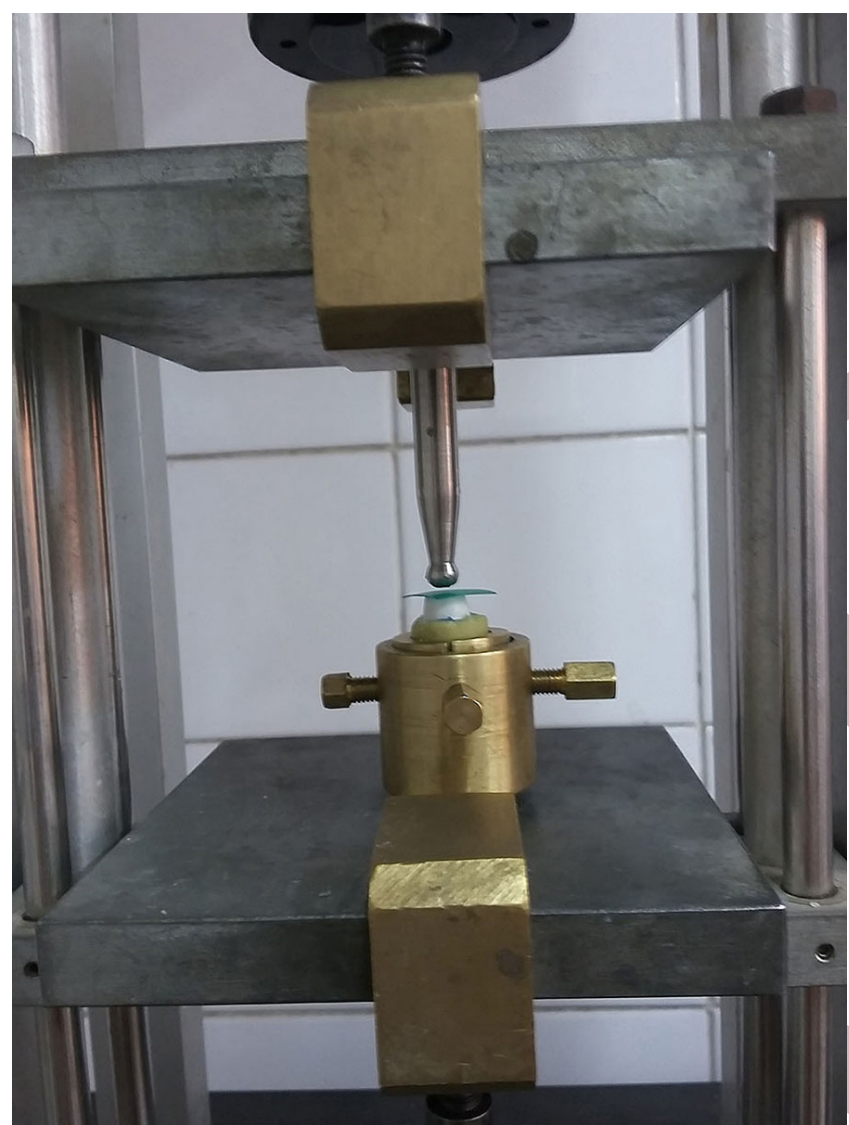

Fig 6: The sample was fixed with the metal ring and the stylus was in the middle of the occlusal surface.

After recording monitor's readings the fractured crowns were inspected and visually examined to determine the fracture mode of each sample. Fractured crowns were photographed using a digital camera for further comparison between samples. The mode of fracture of each sample was determined; depending on the severity of crown damage according to the classification of Burke and Watts (1994) (7) as following (Fig. 7):

- Mode I: Minimal fracture or crack in the crown.

- Mode II: Less than half of crown lost.

- Mode III: Half of crown lost (crown fracture through midline.

- Mode IV: More than half of crown lost.

- Mode $V$ : Severe fracture of crown.

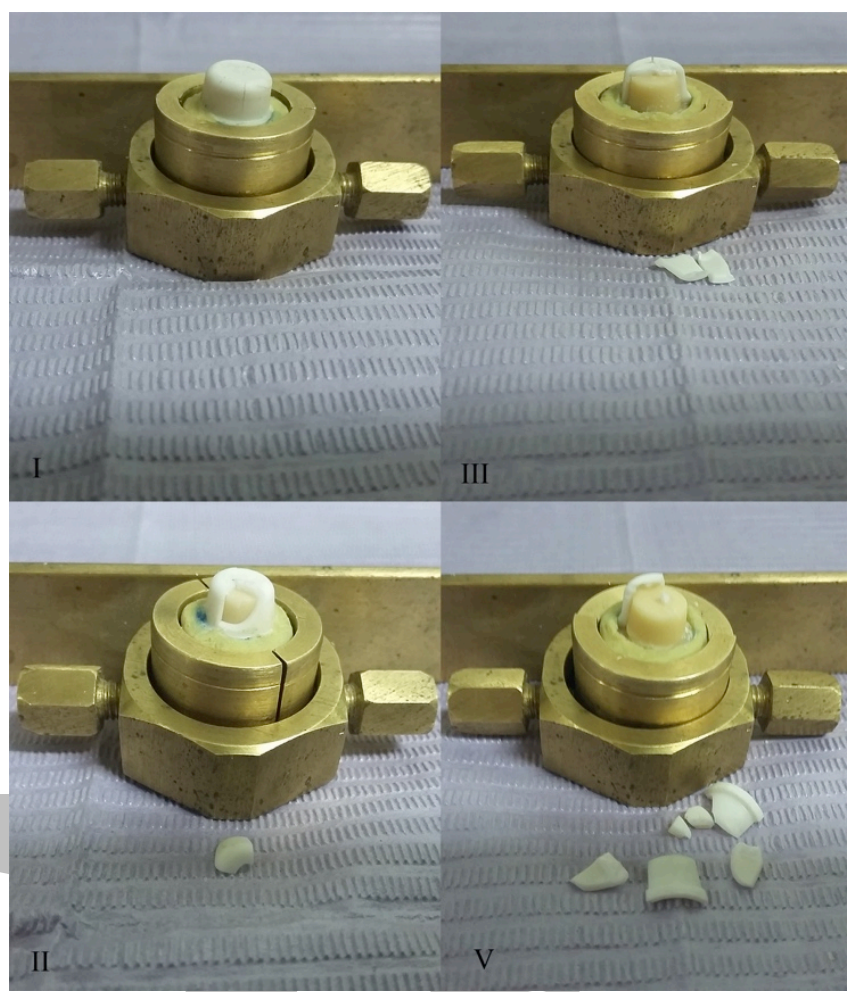

Fig 7: Different patterns of crown fracture.

\section{Statistical analysis}

Were calculated for each group, which include mean, standard deviation, minimum and maximum values. Results of marginal fit and fracture resistance were analyzed using ANOVA test.

A (p-value) of less than 0.05 was considered statistically significant.

\section{RESULTS}

Mean marginal gap and standard deviation in group A $\left(6^{\circ}\right)$ were $(93.50 \pm 4.19 \mu \mathrm{m})$, group B $\left(12^{\circ}\right)$ were $(87.02 \pm 4.73$ $\mu \mathrm{m})$, group $\mathrm{C}\left(22^{\circ}\right)$ were $(79.10 \pm 2.63 \mu \mathrm{m})$. It was found that the marginal gap of group $\mathrm{C}$ was smaller than that of group $\mathrm{A}$ and $\mathrm{B}$, and the mean marginal gap of group $\mathrm{B}$ was smaller than that of group A.

ANOVA test analysis of mean marginal gap difference showed statistically significant difference at $(\mathrm{p}<0.001)$ between the three groups; where Group $\mathrm{C}$ showed significantly lower mean gap (Table 1).

The results of fracture resistance test for cores were collected after testing each group by the load-to-fracture universal testing machine. The highest load was recorded in order to fracture a core was in group C $(1612 \mathrm{~N})$ indicating the strongest cores. On the other hand, the lowest load-tofracture was scored in group A $(702.1 \mathrm{~N})$ indicating the weakest core (least strength).

The means and standard deviations were calculated. The mean value of fracture resistance in group C (1375.76 \pm 193.61) was higher than that of group A $(901.62 \pm 188.30)$ and $\mathrm{B}(1139.16 \pm 96.63)$, the mean value of fracture resistance of group B was higher than that of group A. 
ANOVA test was used to compare the fracture load mean between the three groups. ANOVA test analysis revealed that there was statistically significant difference between fracture resistance of the three groups; (p-Value $<0.003^{*}$ ) (Table 2).

Table 1: Showing statistical analysis of means and SDs of the marginal gap values of the test groups.

\begin{tabular}{|c|c|c|c|c|c|}
\hline Group & Mean \pm SD & $\mathbf{N}$ & $\begin{array}{l}\text { Min. - } \\
\text { Max. }\end{array}$ & Median & $\begin{array}{l}\mathbf{F} \\
\mathbf{P}\end{array}$ \\
\hline Group A & $93.50 \pm 4.19$ & 5 & $\begin{array}{c}86.90- \\
97.20\end{array}$ & 95.0 & \multirow{3}{*}{$\begin{array}{l}16.645^{*} \\
<0.001^{*}\end{array}$} \\
\hline Group B & $87.02 \pm 4.73$ & 5 & $\begin{array}{c}82.30- \\
94.70\end{array}$ & 86.0 & \\
\hline Group C & $79.10 \pm 2.63$ & 5 & $\begin{array}{c}75.70- \\
81.90\end{array}$ & 80.10 & \\
\hline
\end{tabular}

F: F test (ANOVA)

$\mathrm{p}_{1}: \mathrm{p}$ value for Post Hoc test (LSD) for comparing between group A and group B $\mathrm{p}_{2}: \mathrm{p}$ value for Post Hoc test (LSD) for comparing between group $\mathrm{A}$ and group $\mathrm{C}$ $\mathrm{p}_{3}$ : $\mathrm{p}$ value for Post Hoc test (LSD) for comparing between group B and group C *: Statistically significant at $\mathrm{p} \leq 0.05$

$\mathrm{N}$ : number of specimens.

Table 2: Showing statistical analysis of means and SDs of the fracture resistance values (in N) of the test groups.

\begin{tabular}{|c|c|c|c|c|c|}
\hline Group & Mean \pm SD & N & $\begin{array}{c}\text { Min. }- \\
\text { Max. }\end{array}$ & Median & $\begin{array}{c}\text { F } \\
\text { P }\end{array}$ \\
\cline { 1 - 5 } Group A & $901.62 \pm 188.30$ & 5 & $\begin{array}{c}702.10- \\
1176.0\end{array}$ & 920.0 & \\
\cline { 1 - 4 } Group B & $1139.16 \pm 96.63$ & 5 & $\begin{array}{c}990.0- \\
1261.0\end{array}$ & 1148.50 & \multirow{2}{*}{$\begin{array}{c}10.246^{*} \\
0.003^{*}\end{array}$} \\
\cline { 1 - 4 } Group C & $\begin{array}{c}1375.76 \pm \\
193.61\end{array}$ & 5 & $\begin{array}{c}1079.90- \\
1612.0\end{array}$ & 1390.50 & \\
\hline
\end{tabular}

F: F test (ANOVA)

$\mathrm{p}_{1}: \mathrm{p}$ value for Post Hoc test (LSD) for comparing between group A and group $\mathrm{B}$

$\mathrm{p}_{2}: \mathrm{p}$ value for Post Hoc test (LSD) for comparing between group A and group C

$\mathrm{p}_{3}: \mathrm{p}$ value for Post Hoc test (LSD) for comparing between group $B$ and group $C$

*: Statistically significant at $\mathrm{p} \leq 0.05$

$\mathrm{N}$ : number of specimens

\section{DISCUSSION}

This in-vitro study compared the marginal fit and fracture resistance using three different degree of taper in allceramic zirconia copings.

The application of ceramic materials for the fabrication of dental restorations is a focus of interest in esthetic dentistry. Zirconia holds a unique place amongst oxide ceramics due to its excellent mechanical properties. High strength zirconia ceramic can be fabricated by CAD/CAM technique, leading to wide increase in the clinical indications of this metal-free prosthesis, showing more favorable mechanical characteristics compared to the early ceramic materials.

Performing in-vitro experiments that aim to analyze indirect restoration failures characterized by fracture of either the restoration or dental structure is an important method for improving restorative procedures (8). In comparison with clinical investigations is less prone to unpredictable influences. But to get results comparable with the in vivo situation, it is of crucial importance to design a test set-up producing a failure mode similar to that occurring clinically (9). Model materials, testing conditions and the design of the test set up of the current in-vitro study were chosen carefully to stimulate the clinical condition as close as possible.
In the present study, the recommendations for a clinically relevant in-vitro load-to- fracture test for all-ceramic restorations described by Kelly (10) were followed. This recommendation included using a die material with elastic modulus similar to that of dentin. In addition the die preparation according to clinical guidelines, using allceramic fixed crowns with clinically relevant dimensions, and using reliable, commonly used luting cement.

Crown dimensions were standardized by $\mathrm{CAD} / \mathrm{CAM}$ construction of the core to minimize variance of measurements by uncontrolled variation. The only modification that occurred was at the degree of taper to change it according to the test group, without changing any other dimensions.

Tylman (11) recommended a convergence angle of $4^{\circ}$ to $10^{\circ}$ as optimal, however small convergence angles may not be achievable clinically. Mack (12) advised $12^{\circ}$, while Poon et al (13) and Smith et al (14) recommended single crown convergence angle from $12^{\circ}$ to $20^{\circ}$. According to Shillingburg (15) the optimum taper ranges from $14^{\circ}$ for premolars to $24^{\circ}$ for molars. Thus, in the present study $6^{\circ}$, $12^{\circ}$ and $22^{\circ}$ were used.

Cores made of high strength core ceramics gain their strength from the core material. Veneering will increase the load required for failure, provided that there is a stable bond between the veneering layer and core ceramic (16). Imperfections in veneering material on the outside or at the veneer/core interface will allow crack propagation during loading and will thus contribute to failure (17). In the present study, only all-ceramic zirconia core was tested to avoid the influence of the veneer/core interface on the failure process.

The crowns were sandblasted to improve the bond between the luting agent and the ceramic material in this study, all tested cores were sandblasted with $50 \mu \mathrm{m} \mathrm{A12O} 3$ at pressure of 2.5 bar. Wang et al (18) reported that sandblasting with $50-\mu \mathrm{m}$ A12 $\mathrm{O} 3$ particles resulted in an increase in the strength of Y-TZP ceramic.

The cores in the current study were luted to their resin dies by means of Multilink Cement system. Lehmann et al (2004) and Salaverry et al (2013), concluded that Zirconia restorations luted with resin cements were found more resistant to fracture than those luted with conventional cements $(19,20)$.

Cone Beam Computed Tomography (CBCT) imaging provides clinicians with sub-millimeter spatial resolution images of high diagnostic quality with relatively short scanning times (10-70 seconds) and a reported radiation dose equivalent to that needed for 4 to 15 panoramic radiographs (21).

Although the Cone Beam Computed Tomography (CBCT) provided excellent results and compared between the three tested groups, there was no reference to support this study.

The adaptation of copings in the present study was assessed without porcelain veneering because the copings principally define the overall adaptation of veneered crowns 
similar to studies done by Komine et al and Beschnidt et al $(22,23)$.

The marginal gaps were assumed to be within the clinically acceptable range, i.e., not more than $120 \mu \mathrm{m}$ (24). The results revealed that group $\mathrm{C}\left(22^{\circ}\right.$ Taper $)$ recorded smallest marginal gap than group $\mathrm{A}$ and group $\mathrm{B}\left(6^{\circ}, 12^{\circ}\right.$ taper).

The results are in agreement with the results of Beuer (2009) (25) and Da-wei et al (2006) (26), who reported that increasing the convergence decreased the marginal discrepancy of all -ceramic crowns, thus improving the marginal fit.

In contrast the results of this study are in disagreement with Cho et al (2002) (27), who found that decreasing the axial convergence angle of crowns diminished their marginal gap. This contradiction may be related to different fabrication methods. The fiber-reinforced composite crowns were fabricated directly on the master cast, whereas the specimens of this study were produced by CAD/CAM technology.

For mechanical testing, universal testing machine was used to evaluate the fracture resistance of the different core designs, occlusal loading is an important factor; the use of 6 $\mathrm{mm}$ steel sphere for testing fracture resistance was recommended by Soares et al (28), it was shown to be ideal for molars and premolars because it contacts the functional and nonfunctional cusps in positions close to those found clinically.

A cross head speed of $0.5 \mathrm{~mm} / \mathrm{min}$ was used in this study. A wide range of cross head speed was reported in the literature, ranging from $0.5 \mathrm{~mm} / \mathrm{min}$ to $10 \mathrm{~mm} / \mathrm{min}$, according to Hammad (29) and Lertchirakarn (30). The continuous loading method has been adopted by many studies in this field and is easy to perform in comparison to the cyclic loading method till failure.

Regarding fracture resistance the results revealed that group $C\left(22^{\circ}\right.$ taper $)$ recorded higher fracture resistance than that group A and group B. These results are in agreement with the results of Gerami-panah et al (2005) (31). Similarly, it is in agreement with Donge et al (32), Mohamed (33) and Corazza et al (34) who reported that a larger occlusal convergence angle of the abutment increased the fracture strength of all-ceramic crowns, perhaps a larger convergence angle would have greater axial restoration thickness and decreased seating pressure.

On the other hand, the results of the present study are in disagreement with the results of Da-wei et al (26) and Liping et al (35), who stated that no significant differences in fracture resistance were observed with different convergence angles. This contradict may be attributed to use of different material properties and fabrication methods between previous studies and present study.

\section{CONCLUSIONS}

Within the limitation of this study, the following conclusions can be drawn.

- Concerning the marginal adaptation, positive relation was determined between convergence angles and marginal fit of CAD/CAM zirconia core, where 22 degree of taper showed the best fit.

- Regarding fracture resistance, a positive relation was determined between convergence angles and fracture resistance, where 22 degree of taper showed the highest values of fracture resistance.

\section{CONFLICT OF INTEREST}

The authors declare that they have no conflicts of interest.

\section{REFERENCES}

1. Aboushelib MN, de Jager N, Kleverlaan CJ, Feilzer AJ. Effect of loading method on the fracture mechanics of two layered all-ceramic restorative systems. Dent Mater 2007; 23: 952-9.

2. Heidari B, Ardakani ZH. Evaluation the Effect of Change in Convergence Angle of Tooth Preparation and Copping Thickness on Fracture Resistance of All Ceramic Crowns. J Mash Dent 2012; 36: 183-90.

3. Reich S, Wichmann M, Nkenke E, Proeschel P. Clinical fit of all-ceramic three-unit fixed partial dentures, generated with three different CAD/CAM systems. Eur J Oral Sci. 2005; 113: 174-9.

4. Felton DA, Kanoy BE, Bayne SC, Wirthman GP. Effect of in vivo crown margin discrepancies on periodontal health. J Prosthet Dent. 1991; 65: 357-64.

5. Knoernschild KL, Campbell SD. Periodontal tissue responses after insertion of artificial crowns and fixed partial dentures. J Prosthet Dent. 2000; 84: 492-8.

6. Jalalian E, Atashkar B, Rostami R. The Effect of Preparation Design on the Fracture Resistance of Zirconia Crown Copings (Computer Associated Design/Computer Associated Machine, CAD/CAM System). J Dent (Tehran) 2011; 8: 123-9.

7. Burke FJ, Watts DC. Fracture resistance of teeth restored with dentin bonded crowns. Quintessence Int 1994; 25: 335-40.

8. Cormier CJ, Burns DR, Moon P. In vitro comparison of the fracture resistance and failure mode of fiber, ceramic and conventional post systems at various stages of restoration. J Prosthodont 2001; 10: 26-36.

9. Rosentritt M, Behr M, Gebhard R, Handel G. Influence of stress simulation parameters on the fracture strength of all-ceramic fixed-partial dentures. Dent Mater. 2006; 22: $176-82$.

10. Kelly JR. Clinically relevant approach to failure testing of all-ceramic restorations. J Prosthet Dent. 1999 Jun;81(6):652-61.

11. Tylman SD. Theory and practice of prostho-dontics. 7th ed. ST Louis: CV Mosby, 1978.

12. Mack PJ. A theoretical and clinical investtigation into the taper achieved on crown and inlay preparations. J Oral Rehabil. 1980; 7: 255-65.

13. Poon BK, Smales RJ. Assessment of clinical preparations for single gold and ceramometal crowns. Quintessence Int. 2001; 32: 603-10.

14. Smith CT, Gary JJ, Conkin JE, Franks HL. Effective 
taper criterion for the full veneer crown preparation in preclinical prosthodontics. J Prosthodont. 1999; 8: 196200 .

15. Shillinburg HT, Hobo S, Whitsett LD, Jacobi R, Brackett SE. Fundamental of fixed prosthodontics. 3rd ed. Carol Stream: Quintessence Publishing Co; Inc, 1997.

16. Koutayas SO, Kern M, Ferraresso F, Strub JR. Influence of design and mode of loading on the fracture strength of all-ceramic resin-bonded fixed partial dentures: an in vitro study in a dual-axis chewing simulator. J Prosthet Dent. 2000; 83: 540-7.

17. Kelly JR. Dental ceramics: current thinking and trends. Dent Clin North Am. 2004; 48: viii, 513-30.

18. Wang $\mathrm{H}$, Aboushelib MN, Feilzer AJ. Strength influencing variables on $\mathrm{CAD} / \mathrm{CAM}$ zirconia frameworks. Dent Mater. 2008; 24: 633-8.

19. Lehmann F, Eickemeyer G, Rammelsberg P. Fracture resistance of metal-free composite crowns-effects of fiber reinforcement, thermal cycling, and cementation technique. J Prosthet Dent. 2004; 92: 258-64.

20. Salaverry A, Borges GA, Mota EG, Burnett Júnior LH, Spohr AM. Effect of resin cements and aging on cuspal deflection and fracture resistance of teeth restored with composite resin inlays. J Adhes Dent. 2013; 15: 561-8.

21. Sukovic P. Cone beam computed tomography in craniofacial imaging. Orthod Craniofac Res. 2003; 6(Suppl 1): 31-6.

22. Komine $F$, Iwai $T$, Kobayashi $K$, Matsumura $H$. Marginal and internal adaptation of zirconium dioxide ceramic copings and crowns with different finish line designs. Dent Mater J. 2007; 26: 659-64.

23. Beschnidt SM, Strub JR. Evaluation of the marginal accuracy of different all-ceramic crown systems after simulation in the artificial mouth. J Oral Rehabil. 1999; 26: 582-93.

24. McLean JW, von Fraunhofer JA. The estimation of cement film thickness by an in vivo technique. Br Dent J. 1971; 131: 107-11.

25. Beuer F, Aggstaller H, Richter J, Edelhoff D, Gernet $\mathrm{W}$. Influence of preparation angle on marginal and internal fit of CAD/CAM-fabricated zirconia crown copings. Quintessence Int. 2009; 40: 243-50.

26. Da-wei G, Bao-wei Z, Yan G, Young-Jian L. Influence of different convergence angles of prepared teeth on the marginal accuracy and fracture strength of allceramic crowns. Chin J Prosthodont. 2006; 1: 9.

27. Cho L, Song H, Koak J, Heo S. Marginal accuracy and fracture strength of ceromer/fiber-reinforced composite crowns: effect of variations in preparation design. J Prosthet Dent. 2002; 88: 388-95.

28. Soares CJ, Martins LR, Pfeifer JM, Giannini M. Fracture resistance of teeth restored with indirectcomposite and ceramic inlay systems. Quintessence Int. 2004; 35:281-6.

29. Hammad M, Qualtrough A, Silikas N. Effect of new obturating materials on vertical root fracture resistance of endodontically treated teeth. J Endod. 2007; 33:
732-6.

30. Lertchirakarn V, Palamara JE, Messer HH. Patterns of vertical root fracture: factors affecting stress distribution in the root canal. J Endod. 2003; 29: 523-8.

31. Gerami-Panah F, Jalali H, Sedighpour L. Effect of Abutment Taper on the Fracture Resistance of allCeramic Three-unit Bridges. J Dent (Tehran). 2005; 2: 159-67.

32. Dong JK, Oh SC, Kim SD. Fracture strength of the IPS Empress crown: the effect of occlusal depth and axial inclination on upper first premolar crowns. J Kor Acad Prosthodont. 1999; 37: 127-33.

33. Mohamed SA, Hamdy IS, El-Guindy JF. Fracture resistance of milled zirconium oxide crown copings with two different occlusal taper. 2012; 58: 1.

34. Corazza PH, Feitosa SA, Borges AL, Della Bona A. Influence of convergence angle of tooth preparation on the fracture resistance of Y-TZP-based all-ceramic restorations. Dent Mater 2013; 29: 339-47.

35. Li-ping L, Yue-zhao M. Effect of different convergence angles of abutment axial surface on the fracture resistance of GI-II all-ceramic corwns. Chin J Prosthodont. 2008; 1: 5. 